\title{
Deciding on Most Favored Nation Trading Status for China A Case Study Using the AHP to Document Bias and Opinion in Political Decision Making
}

\author{
Tanya Burns \\ George Washington University \\ Jeanine A. Fleming \\ Richard S. Carson \& Associates, Inc. \\ Carl R. Moore \\ Computer Sciences Corporation
}

\begin{abstract}
The decision of whether or not to grant Most Favored Nation (MFN) trading status to mainiand China is a complex undertaking, requiring consideration of many different criteria and sub-criteria. The Analytic Hierarchy Process (AHP) is the modeling tool used to structure the decision factors. The decision support process on China's MFN status is based on six critical criteria, and their associated sub-criteria. The objective is to decide between three alternatives for China: granting MFN status unconditionally, denying MFN status, or granting MFN status conditionally. Conditional MFN status would place restrictions on subsequent renewals based on pending resolution or demonstrated improvements in the criteria areas of concern. The AHP model can then be used to examine the bias and opinions inherent in subjective selection of criteria and priorities in order to critique the rationality of the decision recommendation.
\end{abstract}

Keywords: AHP, China, Decision, MFN, Opinion 


\section{Deciding on Most Favored Nation Trading Status for China \\ A Case Study Using the AHP to Document Bias and Opinion \\ in Political Decision Making}

\section{Introduction}

The purpose of this paper is to develop a case study using the Analytic Hierarchy Process (AHP) to model the decision of whether Most Favored Nation (MFN) trading status should be granted to mainland China. China's MFN status has become highly controversial since the Tiananmen Square Massacre, and is debated frequently in Congress. Using the AHP as a decision support system for such a controversial decision will enable individuals to examine the bias and opinions inherent in subjective determination of criteria and the priorities of those criteria. This allows a critique of the rationality of the decision recommendation.

\section{Defining The Problem}

Granting Most Favored Nation trading status to mainland China is a complex decision governed by a large number of criteria and sub-criteria. The complexity of the decision makes it difficult, if not impossible, to analyze all factors affecting the decision making process without a formal approach to the problem. The Analytic Hierarchy Process provides the decision maker with a formal methodology for hierarchically modeling complex real-world problems. It allows the decision maker to account for all inputs, the relationships between inputs, relative priorities in the decision, and all decision or action alternatives. An AHP decision support model for the recommendation of whether to grant MFN trading status to mainland China enables the many inputs to be tracked in a manner that is understandable and provides clarity to the decision maker despite the size and complexity of the problem. The selected criteria and the priorities assigned in the AHP model also provide insight to the decision making process.

\section{Description of the Model}

The AHP model of the China MFN decision has four primary criteria. These four primary criteria have a number of sub-criteria, and in some cases second level sub-criteria. The AHP model for the China.MFN decision is illustrated in Figure 1 on the following page. A brief description of the modeling process and the rationale for the decision alternatives and criteria follows.

\section{The Modeling Process}

The AHP model for deciding China's MFN trading status was developed in an iterative process of research, discussion, and model update. The modeling team consisted of three individuals with different perspectives on the problem: one favored granting MFN status to China unconditionally, one opposed granting MFN status, and the third team member favored granting MFN status with restriction pending improvements or changes in certain Chinese government policies. The modeling process began with each team member independently producing an AHP hierarchy based on the individual's perceptions of the pertinent criteria and sub-criteria affecting the decision. These criteria and sub-criteria were based on research performed by each individual to determine from public media sources the critical issues affecting the decision. The three models 

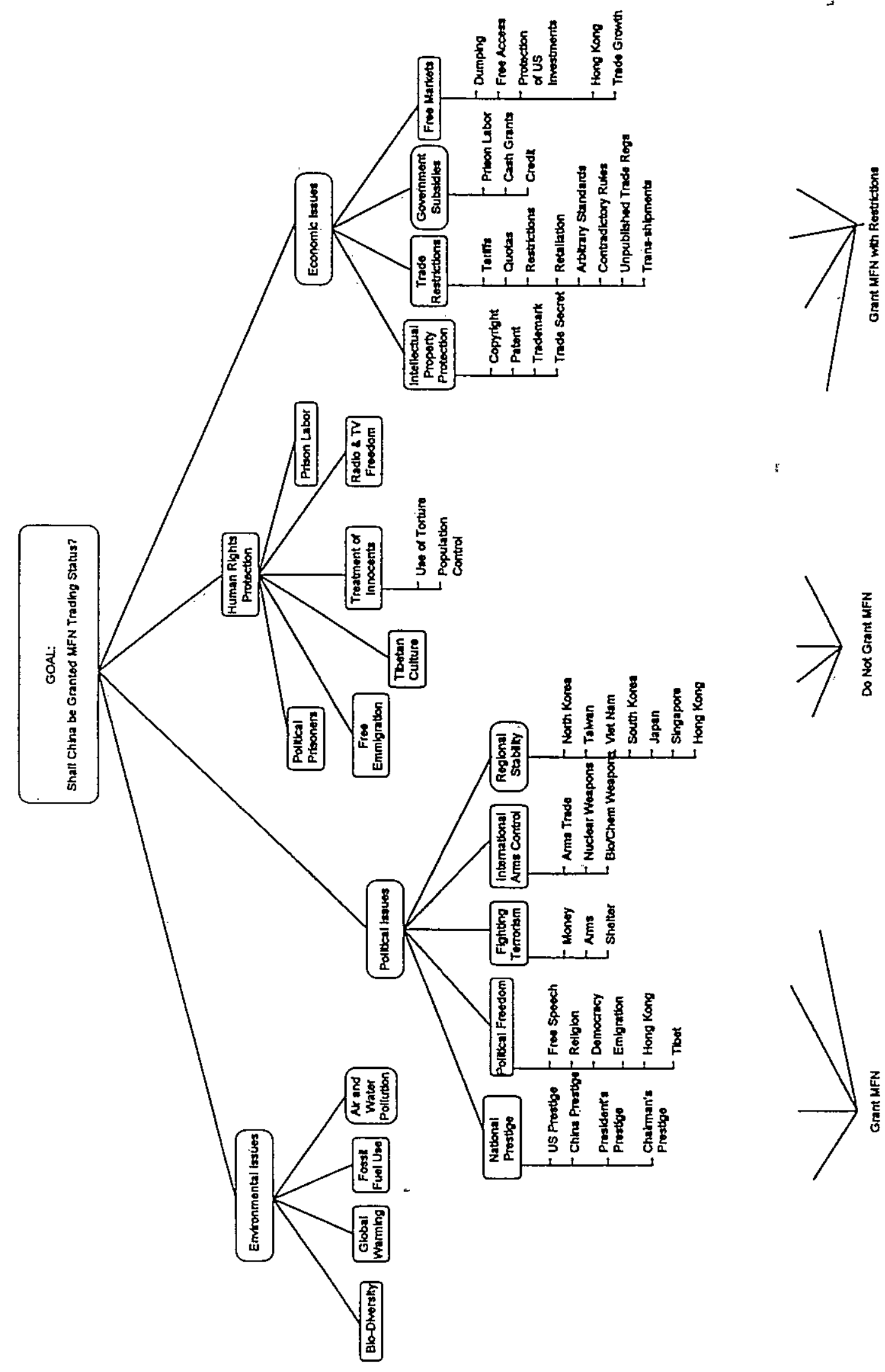

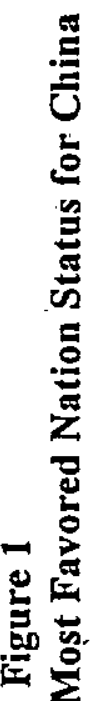

7
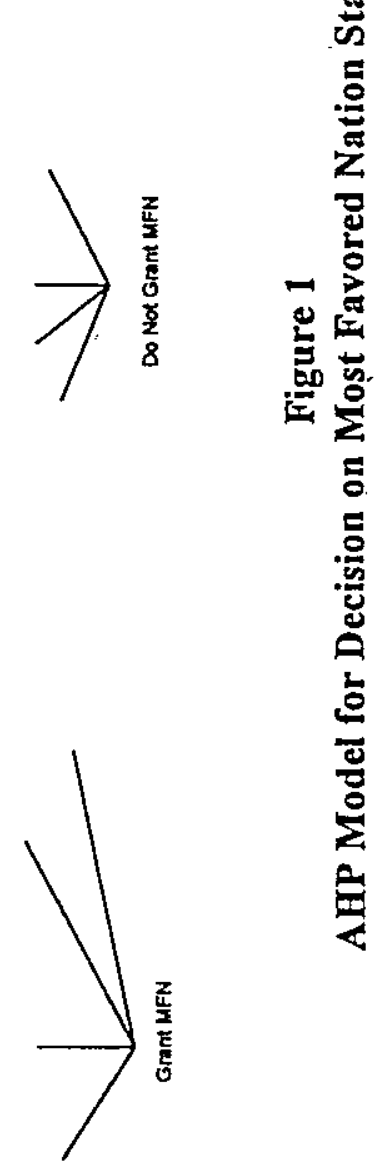
were then compared, and discussions among the three modelers produced an intermediary model that encompassed elements from all three models. However the discussions also produced several questions concerning the relative priorities of several criteria and sub-criteria. Specifically reconsidered was whether some sub-criteria should be elevated in importance to primary criteria, or whether some criteria should be demoted to sub-criteria. For example, a major point of discussion was whether human rights issues should be considered a sub-criteria under the political issues primary criteria or should human rights be elevated to a primary criteria itself. Re-iteration of the research phase revealed a very high level of concern within the US government and in the US general populace about human rights. Consequently, human rights issues were elevated to a primary criteria to reflect the importance placed upon this issue within the United States. This process was repeated several times to clarify issues. Each iteration tended to deal with finer and finer points of dissension in the model, and the issues moved further down the hierarchy. The final iteration produced the AHP hierarchy illustrated in Figure 1.

\section{The Alternatives}

Three alternative decisions have been placed in consideration -- Granting MFN status to China unconditionally, denying MFN status, and granting MFN status with restrictions to encourage changes in China's policies in directions favorable to US foreign policy and economic goals.

\section{Granting MFN Status}

Granting MFN status would be a recognition of China's growing importance in the international community, with the threat of loss of face if China were to do something in the future to endanger this status. This alternative would help to open diplomatic channels to improve human rights conditions within China. Also US industry would be able to establish footholds and business ties in China. The underlying thought is that as the Chinese people come to enjoy the fruits of free trade and the good will of the United States they will pressure the Chinese government to assure favorable ties with the United States by reforming policies which enjoin international reprobation.

Granting MFN status represents the 'carrot' approach to encouraging change in China. However granting MFN status would have the drawback of appearing to sanction China's current policies. This could be seen as a give-away to a regime that has refused to comply with human rights and trade standards demanded by the rest of the world. A decision to grant MFN that is based more on economic concerns, while popular with industry, would be bitterly opposed by political groups. Politically active organizations would view this as a blank check for China to continue with unacceptable polices, especially its human rights policies.

\section{Denying MFN Status}

Denying MFN status would be a punitive measure meant to express the United States' concern with China's lack of progress in reducing human rights abuses and in assuring fair trade conditions. Denying MFN status would have the effect of forcing China to examine its policies and issues in order stem the economic losses it would encounter in the form of trade restrictions in the US market. The objective would be for China to make changes in its polices towards human rights abuses and in restrictive trade policies in order to regain MFN status.

Denying MFN status represents the 'stick' approach to encouraging change in China. However this approach has the drawback of eliminating the US ability to directly influence Chinese policy. 
There would be nothing further the US could do in the event China refused to comply with US demands and elected to get by without MFN status. A further drawback to this alternative could be the imposition of retaliatory restrictions on US trade in China. China represents a vital new market for many US businesses. Any move to restrict or eliminate US businesses from this market could have dire consequences for those US firms doing business in China.

A decision to deny China MFN status based solely on political factors will gain the support of politically-active groups seeking a halt to China's human rights abuses and sales of weapons to third world states. However this decision will be opposed by business interests who see China as a major world market that could be closed to them.

Granting MFN Status with Restrictions

Attaching restrictions to China's MFN status to encourage change in their human rights and other policies to achieve US foreign policy goals will help gain acceptance of the decision by those groups concerned with the political situation in China. These restrictions, while not defined in detail in this briefing paper, could take the form of gradually reduced tariffs over a schedule that would coincide with changes in Chinese policies, or could take the form of a limited time frame for MFN with required reviews to reconsider MFN based on improvements in China's positions. These restrictions would be defined by foreign policy decision makers in light of current foreign policy and economic goals.

This approach avoids appearing to turn a blind eye towards China's human rights violations, arms trading, and other actions which are contrary to US interests. At the same time it avoids instigating retaliatory action by China against US industries seeking to trade in China. The use of restrictions on the MFN status to encourage change in Chinese policy is probably the best approach to achieving positive impact on environmental issues. The lifting of the restrictions as a result of improvements in China's protection of the environment provides incentives for China to institute environmentally sound policies.

\section{The Criteria and Sub-criteria}

Using the modeling process previously described, the four primary criteria which affect the decision on China's MFN status are -- human rights issues, political issues, economic issues, and environmental issues.

\section{Human Rights Issues}

China's human rights policies are at the forefront of the decision of whether its MFN status should continue to be granted. The pictures of the Tiananmen Square massacre, which were splashed over US news networks, are a major contributor to the significance of the human rights issue. The highly publicized news coverage of the Tiananmen Square massacre made the American public acutely aware of human rights abuses in China, and Americans are now demanding that something be done. Gaining progress on the human rights issues with China has been difficult, however, since China does not "believe that the question of human rights should be linked with the question of trade" (Lippman, 1994).

In May of 1993 President Clinton signed an executive order that linked 1994 MFN renewal to demonstrated improvements in China's human rights issues. However, he dropped the link to 
fair trade and nuclear non-proliferation. The factors expressly addressed in the order were prison labor exports, freedom of emigration from China, release of political prisoners, protection of Tibet's cultural heritage, and the free flow of radio and television into China (Chandler and Southerland, 1994). The factors stated in the order, along with China's repression of religion and its treatment of innocent citizens are sub-criteria which have an impact on the human rights criteria. China's treatment of innocent citizens has been further broken down into second level sub-criteria which include China's use of torture and its population control techniques.

Prison labor exports are an issue that factor into both the human rights criteria and the economic criteria. Despite China's promises to discontinue its practice of exporting prison labor products to the US, one monitoring group claims that China still exports products made by prison labor. The prison labor products are disguised by either mixing them with products made from a legitimate factory or by simply re-labeling them (Keatley, 1993).

The population in China has grown at an explosive rate, and is one of the main contributors to its economic growth. To keep the population growth under control, China has instituted a tough family planning policy. Human rights organizations are outraged by the Chinese government's policy of using forced sterilization and abortion to punish offenders who violate the family planning policy (Gibney, Huus, and Whitmore, 1993). Many Americans find the population control policies to be deplorable.

Another human-rights issue of great concern in the US is China's use of torture in its jails and labor camps. Asia Watch has reported numerous accounts of political dissidents having to undergo intense suffering and pain that has resulted in permanent physical and psychological injury (US Senate, 1992). Newsweek reported that the use of torture has become so blatant in China that exhibits at a Shanghai Art Museum featured graphic torture scenes (Gibney, Huus, Whitmore, 1993).

China invaded Tibet in 1950 and has continued to ethnically cleanse the country by sending ethnic Chinese to overrun the population. Unfortunately, Tibetans are not the only people being persecuted in China. China also tries to control the religious worship in its country. The statement of the Puebla Institute in a Senate Finance Committee hearing indicates that after the Tiananmen Square protests China increased religious restrictions (US Senate, 1992). These restrictions were increased because the Chinese government claims that Christians are being used by foreign forces to undermine the Communist regime.

One area in which China has made strides is in its emigration policy. In a 1992 Senate Finance Committee hearing, Hon. Anold Knater, Under Secretary for Political Affairs, told the committee that in 1991 China allowed over 18,000 Chinese to receive visas to the US, and allowed nearly 80,000 nationals to study, travel, and do business in the United States (US Senate, 1992). However, China has been know to react slowly to requests by political dissidents and their families for exit visas to the US. Consequently free emigration is still a factor in the MFN debate.

China appears to have made a small move towards fulfilling the requirements of President Clinton's 1993 executive order. China has released prominent Tibetan political prisoners, has initiated talks with the International Red Cross about monitoring its prisons, and has agreed to allow US customs officials to inspect five prisons suspected of producing export goods with 
prison labor. Although this gives the appearance that some progress has been made, an earlier agreement was signed between China and the Bush administration in 1982 that would have allowed US inspectors into Chinese prisons. Since that time, Beijing has allowed only a handful of inspections (Chandler, 1994). Another indication that the moves made by China concerning human rights issues are relatively minor, falling short of meeting the requirements laid out in President Clinton's executive order, are that Chinese Foreign Minister Qian Qichen has not announced the release of any dissidents, has not allowed foreign news broadcasts into China, and has not improved the conditions in Chinese prisons (Lippman, 1994).

China does not today meet the Western World's human rights standards. However, one CNN corespondent has asked, are China's human rights policies evaluated by how much progress China has made or by how far they have to go to meet world standards? Another question is whether it is right to judge China by Western values. Asian officials argue that the human rights issues fundamentally boil down to differences between Asian and Western values. In a November issue of Newsweek, Chinese spokesman Wu Jianmin stated that “...For Asians, human rights do not mean privileges for the few but of the many." Wu claims that Americans continue to focus on a small number of dissidents rather than seeing the progress China has made in raising the majority of people's living standards (Elliot and Powell, 1993). By systematically evaluating MFN status using the AHP, China might better understand the thought process behind the US decision, especially if the decision is to deny MFN status to China. Using the AHP could also indicate to the US any discrepancies or one-sidedness that has factored into the decision.

\section{Political Issues}

National prestige is an important factor in the MFN status decision. US prestige, Chinese prestige, and the prestige of both country's leaders are issues that must be factored. Both the President of the United States and the Chairman of China must consider how the MFN decision will affect their political image. In the US, this is an extremely important consideration for President Clinton. During the last presidential campaign President Clinton strongly criticized President Bush's policy towards China. If President Clinton does not uphold his strong campaign rhetoric, and unconditionally renews China's MFN status, he could experience a decline in voter confidence. Another element that could affect a US decision is the conditions President Clinton placed on 1994 MFN renewal that might force MFN status to be denied if the conditions are not met. Although conditions were placed on China for continued renewal, modest moves by Chinese leaders in the human rights issues could give enough latitude for continued conditional status.

Additionally, China's Chairman Deng Xiaoping might appear cowardly to the world community and especially within the Asian community. The Chairman is already in a precarious position as his health is failing and he needs to protect his power base. The President must consider the reaction of the Chairman if Deng Xiaoping feels his prestige has been compromised.

When reacting to the decision criteria, neither the US nor China wants to appear too lenient nor bullish in settling the MFN situation. China feels that the United States is interfering with its internal affairs and the United States feels it must protect the citizens of China. The result of being too soft or too hard could negatively impact both country's world images This could lead to increased difficulties in delicate diplomatic situations. The US must also consider how its decision will be perceived by Chinese officials. As Shirley Kan suggests in an article in the July issue of the Far Eastern Economic Review, conditional MFN renewal could appear to China as 
weakened resolve. This will have a greater probability if the 1993 conditions are not met and MFN status is still renewed in 1994.

Political freedom in China is an integral part of the political issues criteria. At the heart of the matter are freedoms cherished by every citizen of the United States. These freedoms, which include the right to democratically select leaders and the right to travel freely in and out of the country, are denied the citizens of the People's Republic of China. They will also be denied the people of Hong Kong when that country is repatriated in 1997.

International arms control is of great importance to the security of the world. According to President Clinton's Executive Order on May 28, 1993, the United States must confront "China's role in the proliferation of dangerous weapons." China is suspected of having sold missile parts to Pakistan in violation of pledges not to transfer such technology. Previously China had assured President Bush that it would abide by the Missile Technology Control Regime, the rules managing bans on missile sales. On March 9, 1992, China acceded to the Nuclear Non-Proliferation Treaty. China has also endorsed application of the International Atomic Energy Association safeguards to itself. However, the entire world still hears reports that China has been selling nuclear and missile technologies to unstable regions, especially Syria, Libya, and Iraq. Given China's refusal to adhere to treaties regarding nuclear, biological, and chemical weapons and arms trading, serious consideration must be paid to ascertain whether China will honor any new pledges. Also many reports suggest that China has funded and continues to support terrorist organizations. This support has allegedly included money, arms, and shelter. These reports must be reviewed to determine if they are substantial enough to create a hindrance for renewing China's MFN status.

Eastern Asia is currently facing very unstable times. The effects of the United State's MFN decision on the stability of the region must be examined. The MFN status could be used as a bargaining chip to pressure China to use diplomatic force in the Far East, especially in regard to the political and military tension between North Korea and South Korea. The refusal of North Korea's leaders to allow nuclear site inspections has created a tense situation involving South Korea and the United States. The US has looked to China to be a strong influence on North Korea to allow the inspections. However, China continues to refuse to intervene. As a permanent member of the United Nations' Security Council, China has the right to veto any sanctions or directives issued by the UN towards North Korea. This potential veto is of great concern to the US.

China considers Taiwan a military threat and has announced that it will use force if Taiwan declares itself an independent country, according an article by Nicholas Kristoff in Foreign Affairs. The full effect of the US's decision to sell F-16 jets to Taiwan remains to be seen.

\section{Economic Issues}

The piracy of US intellectual property, which includes US copyrights, patents, trademarks, and trade secrets, particularly in the areas of pharmaceuticals and computer software, must be a concern in regard to formulation of US policy for renewal of China's MFN status. In past years China has tolerated this piracy, which has resulted in almost $\$ 1$ billion per year in lost export opportunities for American businesses (Baucus, 1992): China agreed to new patent and copyright protections after the United States threatened a block of Chinese exports; however the implementation of the intellectual property agreement must continue to be monitored. 
President Clinton's Executive Order of May 28, 1993, states: "China runs an $\$ 18$ billion trade surplus with the US." The reasons for this inequality date back to 1988 when China began an abstention campaign that resulted in China becoming the most protectionist nation (Baucus, 1992). Included in this program were new trade barriers, including import bans, import licenses, quotas, and discriminatory testing requirements. Additional Chinese restrictions include arbitrary standards and contradictory rules governing imports that often are unpublished or vary from. region to region. Many import items are restricted for unwarranted medical or safety reasons. American businesses argue that the true reasons for the restrictions are to ration scarce foreign exchange or protect China's domestic industries. China has pledged to remove these arbitrary rules on imports such as wheat, citrus fruit, and wood products. These unfair practices, as well as China's evasion of agreements and US import quotas by mislabeling products or shipping products through third world countries, must be discontinued.

Government subsidies are another area in which China's progress must be evaluated. As previously discussed, China has a reputation for employing prison labor to manufacture export goods. The US placed a moratorium on these goods, yet the Custom Service continues to seize apparel, tools, and many other products suspected of being made by prison labor. Other financial assistance China gives to Chinese firms includes cash grants and credits. These subsidies compensate the firms for losses as a result of selling their products at lower rates in the foreign markets. This results in a competitive advantage for the Chinese firms in the markets, and has outraged many American businesses.

Despite their $\$ 18$ billion trade surplus, China continues to block American goods. The President's executive order states that the US would "pursue resolutely all legislative and executive actions" to ensure that China abides by commitments in trade issues. These commitments include a reduction in China's dumping of its products, and increasing US companies' access to Chinese markets. China announced in 1991 that all subsidies to Chinese firms would be eliminated to stop the indiscriminate dumping. In October of 1993, China stated that it would remove most barriers against foreign goods within five years. However, China's history of disregarding the agreements it has made dictates that China's adherence to the policy be closely monitored.

The effect of the MFN resolution on US investments currently in China must also be examined. The following companies have substantial investments in China: Coca-Cola's total investment in China will be $\$ 500$ million by 1996; Motorola expects to install cellular systems in over 100 Chinese sites; Xerox Corporation announced $\$ 70$ million in sales in 1992, up 20\% from the previous year; Proctor \& Gamble, Johnson \& Johnson, and H. J. Heinz have announced plans to open plants in northern cities in China (Engardio, March 29, 1993). A total of nearly $\$ 5$ billion has been invested in manufacturing ventures as of early 1992 (Rondinelli, Summer 1993). According to a report to the Subcommittee on Technology and National Security of the Joint Economic Committee, the total US 1992 utilized direct investment in China was $\$ 500$ million. All these investments are at risk should China's MFN status be denied.

The rapid growth of China's economy must also be regarded as a possible loss of revenue for US firms exporting to China should MFN status be denied. An article in Time (November 29, 1993) states that China's economy has been growing at a rate of $9 \%$ per year. Its gross domestic product increased $12.8 \%$ in 1992 . China now has the third largest economy in the world. The 
repatriation of Hong Kong in 1997 will greatly increase China's economy. Hong Kong is one of the easiest countries in which to invest or sell products because there are no foreign exchange controls or restrictions on repatriation of profits and no controls on foreign ownership.

\section{Environmental Issues}

As China emerges as an industrial economy, a key concern is their contribution to global warming. Currently China is the third largest emitter of greenhouse gases (Kristof, 1993). However, while other industrial nations, including the US, are actively pursuing means to reduce or eliminate emissions which contribute to global warming, China has shown no interest in addressing environmental policies that could slow or limit its own economic growth. China currently has the fastest growing economy in the world. The Stockholm Environment Institute has calculated that by the year 2025 China will produce three times as much carbon dioxide as the US if its economy continues to grow at its current rate (Kristof, 1993).

Closely associated with increased emissions of global warming gases is China's use of nonrenewable natural resources. Fueling the industrial buildup is an ever increasing appetite for oil and natural gas. As these commodities become scarcer, their unrestrained use in China could cause economic distortions due to shortages, as well as increasing international tension as nations vie for the decreasing supply. Granting MFN status to China, and thereby continuing to open US and world markets to its economy, could increase the growth rate and consequently increase the global warming gas emission rate and the rate of use of natural resources.

Another area of concern is the impact of the Chinese economy on the quality of the world's air and water. Any industrial activity has a certain level of effluent associated with it; however, leading industrial nations in North America and Europe have recognized the importance of balancing economic growth against the protection of the environment. China is not willing to make that commitment. China's emphasis remains firmly rooted in unrestrained economic growth, with little concern for the environment. Air pollution in many Chinese cities has been reported to be appalling, and the emission of sulfur dioxide from coal buming power plants and industrial furnaces is already producing acid rain effects in Korea and Japan. Further, the unrestrained discharge of industrial effluent into China's rivers and coastal basins is adversely impacting the water quality in many areas of Southeast Asia. As with the producing of global warming gases, a grant of MFN status could further fuel China's economy and increase the rate of environmental destruction to air and water.

China also shows little concern for biodiversity issues. There is a thriving market in China for animal products from endangered species such as black bear livers, tiger claws, elephant tusks, and rhinoceros horn. The continued importation of these otherwise outlawed animal products encourages further poaching of these animals. In addition, the increase in pollution and toxins introduced into China's environment is having a deleterious effect on many species native to China. An example is the giant panda, a species nearing the brink of extinction that cannot be found elsewhere in the world. Any political decision that encourages further unrestrained economic expansion in China will fuel further depredations of plant and wildlife.

These potential side effects of MFN status, although currently popularly viewed as minor compared to human rights and economic issues, must be considered when making a decision. As with human rights, China must be encouraged to improve policies concerning environmental 
protection. Conservation of natural resources, protection of the environment, and preservation of endangered species must become as important to China as they are to Western nations if the global environmental is to be protected. From China's point of view, environmental restrictions imposed by the US, which could hurt China's economic growth, are unfair since the US showed no concern over the environment during its own industrial revolution. In fact, up until the past ten years the US was one of the worlds largest polluters. Such an argument warrants little merit today, however, since the world is more aware today of environmental dangers and their detrimental effect on society than it was during America's growth period.

\section{The Value of the AHP Method in Political Decisions}

Making a political decision, such as whether to grant MFN status to China, is a subjective process. The criteria and sub-criteria typically found in political decisions cannot be measured objectively. Even choosing criteria and sub-criteria is subjective, being based on the opinions and biases of the decision maker and/or AHP model maker. Each criteria and priority are a subjective judgment based on published accounts, experience, public opinion, and personal knowledge of the model builder. An important value then in the AHP method in political decisions lies in documenting the opinions, bias, and prejudice underlying the final decision.

The assignment of priorities to each criteria, sub-criteria, and alternative in the AHP hierarchy is even more subjective than choosing the criteria and sub-criteria. These priorities can be easily manipulated to result in any of the alternatives as a desired decision. For example, using the hierarchy for China's MFN status developed in this paper, a conservative politician oriented towards world economics and trade might assign a higher priority to economic issues and associated sub-criteria since they would materially affect the ability of US businesses to expand into and profit from the Chinese emerging markets. These priorities would likely produce a decision to grant MFN status to China in order to keep the trade doors open for American business interests. On the other hand a liberal politician, more concerned with China's record of human rights abuses, might place a higher priority on the human rights issues and the associated sub-criteria which indicate an unwillingness for China to comply with generally accepted world standards for the treatment of citizens. These priorities quite likely would produce a decision to deny China most favored nation trading status as a punitive measure for its failure to correct human rights abuses. Both politicians could point to the AHP model and claim to have made the best decision, yet the outcomes are polarized. The value of the AHP model lies in providing other individuals the ability to look into the decisions to determine which criteria and sub-criteria were most important to the decision maker.

As the world becomes more a global village, and nations are less insulated from the effect of other nations and cultures, the ability to better understand the motivations of other countries and their peoples becomes more important. The use of AHP models to make key decisions, and the ability of these models to document the underlying opinions and bias' of the decision makers, could be important tools in improving the level of understanding between nations and cultures. For example, the use of the hierarchy presented here to recommend a decision on granting MFN status to China would explicitly show the Chinese government the final decision and also the reasoning and opinions behind the decision. In the case of China's MFN status, the decision maker is the President of the United States. 
Review of the AHP model could help the Chinese government and the Chinese people to better understand what is important to the US government and US people. This understanding could be very important in an area such as human rights where the rights of the individual citizen versus the rights of society are seen very differently by the two cultures. If China where to build an AHP model for the MFN status decision, based on the opinions and bias prevalent in China, the US would be able to better understand the view point of China in international relations and issues. This type of insight for each side, as well as the comparative documentation offered by the models, could be invaluable in bringing two divergent cultures, such as the US and China, closer to a mutual understanding.

A final point about the value of the AHP model in political decisions is the historical record the model provides for critical national and international decisions by our county's leaders. In less than a year or two from now the public memory of key issues and the priorities behind the MFN status decision for China will have faded. The ability to look back and understand the underlying opinions and bias held by the decision maker would provide invaluable knowledge to society. Consider how historically enlightening it would be to have had an AHP model of Kennedy's decision to send advisors to Viet Nam in the early 1960s, or of Roosevelt's decision to launch the New Deal in the 1930s. Insight and understanding of these events, as documented by the decision maker in the form of an AHP model, would be invaluable in understanding the rationality behind decisions in terms of the decision maker's opinions and bias as documented in the model. By seeing what criteria and sub-criteria were considered important, and from an absence from the model what was considered unimportant, as well as seeing the relative priorities assigned to each criteria and alternative, historians could better understand how key decisions were made and what factors might have changed those decisions. While we are unable to back up and obtain AHP models for past decisions, they can be made available for future generations who want to better understand decisions made today which will shape their future.

\section{References}

Awanohara, Sutsumu. "Breathing Space”. Far Eastern Economic Review, June 10, 1993.

Baucus, Max. "Developing China Policy". The China Business Review, March-April, 1992.

“The Case for China's MFN Status". The China Business Review, July-August, 1992.

Central Intelligence Agency. China's Economy in 1992 and 1993: Grappling With the Risks of Rapid Growth, July 30, 1993.

Chandler, Clay. "U.S. - China Accord Said Near: Trade Status Endangered, Bentsen Warns Premier". Washington Post, January 20, 1994, page A:17.

Chandler, Clay; and Southerland, Daniel. "China Moving Slowly on Rights Issue: Steps May Yet Meet Minimum Demands Set For Trade". Washington Post, January 21, 1994, page A:25.

"Chinese Fizz". The Economist, January 29, 1994. 
Elliott, Michael. "Swordless in Seattle". Newsweek, November 29, 1993.

Engardio, Pete; Curry, Lynne; and Barnathan, Joyce. "China Fever Strikes Again". Business Week, March 29, 1993.

Gibney, Frank Jr.; Huss, Kari; and Whitmore, James. "The Great Stonewall”. Newsweek, June 7, 1993.

Goldstein, Carl. "Jerky Movements". Far Eastern Economic Review, February 17, 1994.

Heenan, David A. "China on the Move". Joumal of Business Strategy, Spring 1993, Pages 35-40.

Kan, Shirley A. "Clinton's China Syndrome". Far Eastern Economic Review, July 1, 1993, page 23.

Keatley, Robert. "Trade Rights, as Well as Civil Rights, Will Factor Into China's MFN Status". The Wall Street Journal, June 4, 1993, page A:10.

Kristof, Nicholas D. "The Rise of China". Foreign Affairs, November/December 1993, pages 59-74.

Lippman, Thomas W. "U.S. Says China Lagging on Human Rights Issue". Washington Post, January 25, 1994, page A:16.

Nelan, Bruce W. "Watch Out for China". Time, November 29, 1993.

Rondinelli, Dennis A. "Resolving U.S. - China Trade Conflicts". The Columbia Journal of World Business, Summer 1993, pages 66-79.

United States President. Executive Order. "China: Most Favored Nation Status". U.S.

Department of State Dispatch, Volume 4, Number 24, June 14, 1993.

United States Senate. Committee on Finance. Extending China's MFN Status, 102nd Congress, 2nd Session. Government Printing Office, July 30, 1992. 